\title{
PRODUCTIVIDAD SALUDABLE
}

\section{VICENTE SAUCEDO}

- Profesor de Dirección del Talento

Facultad de Economía y Empresa, Universidad Europea, España

\section{RESUMEN}

Los hábitos alimenticios pueden estar relacionados con la productividad de los trabajadores; así lo exponen diferentes estudios. Los hábitos de mantener una alimentación saludable permiten prevenir la aparición de diferentes tipos de enfermedades. El estrés y las presiones laborales pueden mermar la capacidad de los trabajadores de analizar el entorno de manera objetiva; y asimismo, llevar a desórdenes alimenticios. La relación entre la alimentación y la productividad se presenta también a nivel interno en el organismo, a través de la acción de neurotransmisores. Se resalta entonces la importancia que tiene la alimentación en el bienestar general de una persona.

Palabras clave: Nutrición, inteligencia emocional, productividad laboral.

\section{ABSTRACT}

As indicated by different studies, eating habits and work productivity can be related to each other. These habits prevent different types of diseases. Labour stress, for example can reduce the worker's ability to analyse his environment objectively; and it can generate eating disorders, which can further reduce labour productivity.

In fact, this relationship is also found within the human body through neurotransmitter dynamics. This essay highlights the importance of nutrition in labour output, as well as, in the worker's well-being.

Keywords: Nutrition, emotional intelligence, labour productivity.

¿Nuestros hábitos alimentarios están relacionados con la productividad? ¿Y si esta relación se convirtiera en algo estratégico? No solo es un hábito como tal, no solo es salud. Hasta las organizaciones internacionales alertan de medir y de adoptar estrategias tomando en serio este aspecto organizacional, ya que solemos devorar la comida en momentos de tensión, excedernos en las cantidades a pesar de lo que sea suficiente para nuestro cuerpo, etcétera. Esa es la hoy llamada alimentación emocional. Sí, algo tan habitual y humano como alimentarnos puede llegar a convertirse en una metáfora entre la forma en que vivimos y la manera como gestionamos nuestras emociones.

La alimentación emocional se refiere a aquellas conductas alimentarias influenciadas por las emociones y los estados de ánimo de las personas; en definitiva, hábitos. Esta relación entre alimentación y emociones es lo que permite discernir entre una necesidad biológica y otra emocional a la hora de comer. La primera está asociada con comer para saciar el hambre y mantenernos vivos; la segunda se manifiesta por el deseo imperioso de comer como consecuencia de nuestro estado de ánimo. En este último caso, el sentimiento de vacío o malestar es calmado con una ingesta desproporcionada de comida, sobre todo rica en grasas. Otras personas buscan alimentos dulces (chocolate, galletas, helado); incluso, las hay que sienten que deben estar constantemente comiendo para calmar su desazón.

Partamos de la base de que no es cierto que los seres humanos seamos seres racionales por excelencia y únicos en ello. Somos, como mamíferos, seres emocionales, y usamos nuestra propia razón cuando es conveniente y para justificar u ocultar emociones. Creer que nuestros hábitos alimentarios son los que deben ser no lleva razón siempre: seguramente es una opinión con la cual uno está cómodo, del mismo modo en que estaría cómodo quien pensase lo contrario. Nuestro shen, nuestro propio espíritu en calma, nuestra salud, es nuestra posesión más valiosa, y se ve afectada por nuestros propios estados de ánimo, que van a influir en nosotros, en muchas ocasiones sin que lo sepamos.

\section{RELACIÓN CON LA BAJA PRODUCTIVIDAD LABORAL}

Ya desde hace años, organizaciones muy relacionadas con el mundo laboral y de la productividad —como la Organización Internacional del Trabajo ${ }^{1}$ (OIT) - alertan permanentemente sobre la estrecha relación entre la alimentación de los trabajadores y el PBI, el consumo y el empleo, llegando a cuantificar el impacto de una mejora alimenticia en la productividad de las empresas, indicando que una nutrición no adecuada genera una reducción de hasta 30\% en dicha productividad.

1. La OIT es la agencia de las Naciones Unidas especializada en temas de trabajo. 
Así, en estudios como el Food at Work. Workplace Solutions for Malnutrition, Obesity and Chronic Diseases², de la OIT, se presenta información de cómo aportan las distintas prácticas en el suministro de alimentos en los lugares de trabajo, mostrando que los programas que proporcionan un acceso cómodo a una alimentación saludable pueden contribuir a prevenir enfermedades crónicas, como la obesidad, la diabetes y los problemas cardiovasculares. Dicho estudio señala, además, que las inversiones empresariales en alimentación se recuperan por una reducción de los días de enfermedad y de los accidentes laborales, y por un aumento de la productividad. Por último, resalta como clave la conexión entre la falta de alimentación y la aparición de fatiga y somnolencia, con las consiguientes consecuencias negativas sobre la seguridad de los trabajadores.

Nuestro compromiso con la productividad no siempre es fielmente cumplido, ya que, a pesar de los esfuerzos por concentrarnos y lograr mejoras, no logramos un resultado positivo. Hay quienes, a pesar de sus buenas intenciones, se ven afectados emocionalmente a lo largo de la jornada. Esta la inicia con una actitud constructiva y pro-positiva, pero, a la mitad de la misma, ya se sienten agobiados, cumpliendo al mínimo y con deseos de que llegue la hora de la salida. Es muy probable que esas personas que quieren y no pueden enfrenten un problema fisiológico provocado principalmente por malos hábitos de alimentación y de descanso. El dicho "oremos por una mente sana en un cuerpo sano"3, del poeta romano Juvenal, es fundamental para la productividad personal y laboral: nuestro cuerpo precisa nutrientes para estar a la altura de las circunstancias. En un entorno adverso, los requerimientos nutricionales son claves para el éxito.

Sin una buena alimentación, las capacidades intelectuales se ven mermadas. La tolerancia a cambios, urgencias y conflictos en el trabajo puede disminuir significativamente, afectando con ello el rendimiento, la capacidad de aprendizaje y hasta el entusiasmo por hacer las cosas bien y a la primera. Es muy común que empresarios o jefes de organizaciones pasen por alto este último aspecto. El trabajador ideal para ellos es el que se comporta más como una máquina que como un ser humano. Sin embargo, es un hecho que hasta las máquinas requieren de un buen combustible y de engrasado, además de una excelente fuente de energía y de un mantenimiento preventivo en tiempo y forma.

Por ello, en nuestras estrategias conviene tener siempre a las personas como centro de decisión, ya que ellas son las que dan vida, son las que innovan y las que transforman la empresa. Este capital humano, desde una concepción básica de la persona junto a sus hábitos y costumbres, estará en el centro de nuestras opciones.

2. International Labour Organization (ILO, 1996-2017), página web: http://www.ilo.org/inform

3. En latín, orandum est ut sit mens sāna in corpore sānō.

\section{ESTRÉS, HÁBITOS Y ALIMENTACIÓN EMOCIONAL}

Hoy vivimos ante dos fuerzas claves de cambio: una transformación constante del entorno y una multiplicación hiperbólica de la información que recibimos. ¿Podemos controlarlo? Aparecen estrés y presión y, cuando estamos estresados, cuando estamos agobiados, se nos corta el flujo sanguíneo de la parte frontal del cerebro, y entonces solo queda el animal de lucha y huida. Por ello, es necesario aprender a gestionar nuestro estrés y nuestra ansiedad, a regular nuestros estados emocionales $\mathrm{y}$, sobre todo, a adquirir mayor conciencia de nuestros propios pensamientos y emociones. Cuando una persona está agobiada por un asunto, no es capaz de pensar con claridad la solución al problema. Cuando surge uno, lo más importante es intentar mantener la calma y comenzar el proceso de análisis y de posibles soluciones, definiendo y redefiniendo el problema tantas veces como sea necesario: identificar el qué, el quién, el porqué, el para qué, el cuándo, el cómo y el dónde. Sentir estrés, sea por la razón que sea, nos lleva generalmente a sentirnos agobiados, y el agobio nos priva de una perspectiva real y objetiva de la situación que afrontamos; por ende, no podemos ver claramente vías prácticas de solución.

Entre la alimentación y las emociones existe un complejo vínculo. Tan es así que se denomina con frecuencia al intestino como nuestro segundo cerebro, pues todo lo que comemos puede tener su causa en las emociones $\mathrm{y}$, de igual manera, nuestra dieta puede condicionar nuestro estado anímico y emocional. Muchas veces hemos dicho que comemos por placer. La comida no solo tiene una función nutritiva; además, el acto de comer es placentero, desestresante. Por ello, cuando nos sentimos cansados, podemos ir en busca de comida; cuando estamos tristes, muchas veces no nos cabe bocado; y cuando comemos con nervios, la comida nos cae mal. En casos extremos, las emociones pueden afectar negativamente la digestión, provocando un síndrome de intestino irritable que condiciona posteriormente la calidad de la dieta. Dormir poco está relacionado con la obesidad, pues la falta de sueño genera estrés y se incrementan en el organismo hormonas que elevan los deseos de ingerir alimentos.

Cuando comemos para calmar nuestras emociones, escogemos más alimentos grasos, lo cual puede desencadenar un exceso de grasas en la dieta, desequilibrando la misma y causando enfermedades. Esto es así porque nuestros antepasados pasaban mucho tiempo sin comer y en actividad, lo cual es una situación estresante, y su cuerpo se adaptó genéticamente para que, al momento de tener comida, escogiesen estratégicamente los nutrientes más concentrados en energía, como lo son las grasas. Entonces, las grasas se asocian a una disminución del estrés en nuestro cerebro. Así, cuando estamos muy cansados quizá reduzca más el estrés un pastel con nata que una manzana. 
En muchos casos no somos realmente conscientes, pues estamos ante nuestros propios hábitos, los que necesitamos por el mismo hecho de ser seres humanos. No podemos vivir sin ellos: la vida sería demasiado complicada si tuviéramos que pensar conscientemente y tomar decisiones sobre todo lo que hacemos. Eso sí, pensemos que nada es perdurable... salvo el cambio. Serenidad y conexión emocional deben ser nuestras metas.

Cuando comemos de manera desequilibrada estamos cuidando mal de nosotros mismos y de nuestro presente. Desahogarnos a través de la comida y subir de peso es solo un síntoma que se recrea en un círculo vicioso. En este sentido, cada vez que comemos de manera compulsiva estamos reforzando la creencia de que la única forma de tener lo que queremos es dándonoslo nosotros mismos, a través de la nutrición.

\section{¿CÓMO REACCIONA NUESTRO SISTEMA ENDOCRINO? ADRENALINA Y NORADRENALINA}

La adrenalina es un neurotransmisor liberado por el cerebro en respuesta al estrés. Es una hormona secretada por las glándulas adrenales ante una situación de peligro. La liberación de adrenalina estimula al máximo el sistema cardiovascular. Cuando se experimenta una emoción muy fuerte, la liberación de adrenalina es la responsable de que suban la presión arterial y la frecuencia cardiaca. Así, cuando realizamos ejercicios de alta intensidad (tales como el sprint o el levantamiento de pesas), el cuerpo aumenta la producción de adrenalina por seis veces o más.

Este neurotransmisor es metabolizado en el hígado y se elimina por la orina. Su formación se da a partir de la noradrenalina, utilizando la ruta común que usan todas las catecolaminas, como dopamina, L-DOPA, noradrenalina y adrenalina. Su biosíntesis se encuentra exclusivamente controlada por el sistema nervioso central.

La noradrenalina puede actuar como hormona (denominada hormona del estrés) y como neurotransmisor, y cumple funciones fisiológicas y homeostáticas. La forma en que sintetizamos esta hormona es a través de la médula suprarrenal (formada por células inervadas por células simpáticas del sistema nervioso autónomo). Se libera en sangre produciendo efectos de activación en nuestro organismo y preparándonos para responder.

En términos generales, la noradrenalina puede actuar como un tipo de neurotransmisor o como un tipo de hormona. Como neurotransmisor, se encargará de transmitir información en forma de impulsos eléctricos a las distintas partes del organismo; desarrolla la activación de nuestro cuerpo en relación con la ansiedad. Se libera en sangre después de ser sintetizada por el aminoácido tirosina.

En cuanto a las funciones de la noradrenalina como hormona, podemos destacar la estimulación de la producción de adrenalina en el cuerpo, provocando un incremento en la actividad de vigilancia y facilitando la atención focalizada y la mejora en la capacidad de reacción conductual ante posibles acontecimientos peligrosos.

Para que, como resultado final, se produzca mayor cantidad de noradrenalina en nuestro organismo, debemos consumir proteínas: alimentos como pescado, carnes, queso y legumbres son grandes fuentes de tirosina. Si ingerimos alimentos como los que hemos mencionado y añadimos a la lista manzanas, plátanos, remolacha, sandía y germen de trigo, contaremos con una buena dosis de tirosina en nuestro organismo, que se encargará de sintetizar las catecolaminas; entre ellas, la noradrenalina.

\section{CONTRARRESTAR EL MALESTAR CON UNA BUENA ALIMENTACIÓN}

En realidad, cuando nos tomamos una golosina porque nos sentimos tristes, abatidos o deprimidos, lo que estamos haciendo es reforzar este estado de ánimo. Así pues, el círculo vicioso que se crea provoca una nueva necesidad de seguir alimentándose de ese tipo de productos. A veces promueve incluso un deseo irrefrenable. Si regresamos a nuestros propios orígenes, solíamos comer lo que las plantas fabricaban de manera natural. Ahora nos alimentamos de lo que se fabrica, digamos, de modo artificial.

Aquí me viene a la mente una frase memorable de Oscar Wilde, cuando nos dice: "Amarse a uno mismo es el inicio de un romance que dura toda la vida"4. Y así debemos entenderlo. ¿Qué debemos proponer? ¿Por qué hemos de ser diferentes en nuestros hábitos y costumbres tanto tiempo utilizados? Saber que diferente no siempre significa ser mejor, solo ser diferente... Por miedo a la crítica, no dejes de hacer lo que más conveniente pareciera ser. Así, el primer planteamiento es preguntarnos cómo modificar nuestro estilo de vida y de alimentación para lograr este cambio en las costumbres.

Curiosamente, los alimentos sí tienen el poder de contrarrestar el malestar general. Es decir, la depresión, la tristeza o el decaimiento pueden ser combatidos con la dieta. Sin embargo, esta tiene que ser adecuada y sana, como aquellas que contienen alimentos con un alto nivel de triptófano, aminoácido que estimula la liberación de serotonina y nos relaja al tiempo que nos vuelve más felices. Esos alimentos son, por ejemplo, el chocolate, el plátano, las nueces y el yogur.

La asociación que existe entre la alimentación y nuestras alteraciones del ánimo refleja un comportamiento alimentario inadecuado. Se trata de definir mecanismos que posibiliten a los sujetos el enfrentarse a sus problemas sin recurrir a la comida y que, a su vez, permitan regularizar sus pautas alimentarias. 
Sin que ello suponga ningún decálogo o consejos cerrados, propongo como primera medida cinco pasos clave: i) lleva un registro de alimentos diarios; ii) pregúntate: ¿se trata realmente de hambre o es un ataque de ansiedad?; iii) disminuye los niveles de estrés ayudándote con ejercicio físico, rutinas de paseo diarias, desarrollo de aficiones y de ocio, etcétera; iv) buscar apoyo cercano o profesional (psicólogo, coaching nutricional, etcétera); y, finalmente, v) apuesta por un ambiente saludable, evitando tener dulces y comida rápida en tu lugar de trabajo y, claro está, también en tu hogar.

\section{¿POR QUÉ UNA DIETA SALUDABLE NOS HACE SENTIR MEJOR?}

Una dieta saludable nos ayuda a sentirnos bien, pues en el intestino existen muchas terminales nerviosas que envían información al cerebro. Por lo tanto, prevenir alteraciones intestinales, así como llevar una dieta de buena calidad, nos ayuda a mantener bajo control las emociones. Una dieta suficiente en micronutrientes, con buena cantidad de fibra soluble, de probióticos y de agua, es un mimo a nuestro aparato digestivo y al segundo cerebro del organismo.

Napoleón decía que un ejército marcha sobre su estómago: así era el compendio de un plato de legumbres, un par de piezas de fruta y un trozo de pan. Esta era la dieta que, hace cientos de años, llevaba usualmente un legionario romano que combatía frente a las hordas de bárbaros en el norte de Gran Bretaña. Un legionario que se preciase necesitaba muchas proteínas para mantenerse musculoso y resistente. La dieta del legionario era abundante y nutritiva, basada en los cereales. Nunca faltaron carne, verduras, frutas y lácteos, frescos o en conserva. Y, claro está, costumbres sanas como agua justo en ayunas —pues han sido muchas horas sin ingerir líquidos durante el sueño-y lo que hoy se promueve como descubrimiento, siendo historia: esa dieta a base de trigo y aceite de oliva que, al no haber azúcar, se endulzaba sanamente con miel.

¿Cómo vamos a aprender si no admitimos que nos equivocamos? Reflexionemos, actuemos en consecuencia y trabajemos a partir de ello. Y todo desde el criterio de que los pensamientos y las reflexiones nos deben llevar a actos $\mathrm{y}$, repetidos estos actos, a cambiar los hábitos; a paladear cada momento... y a alcanzar la serenidad necesaria. 